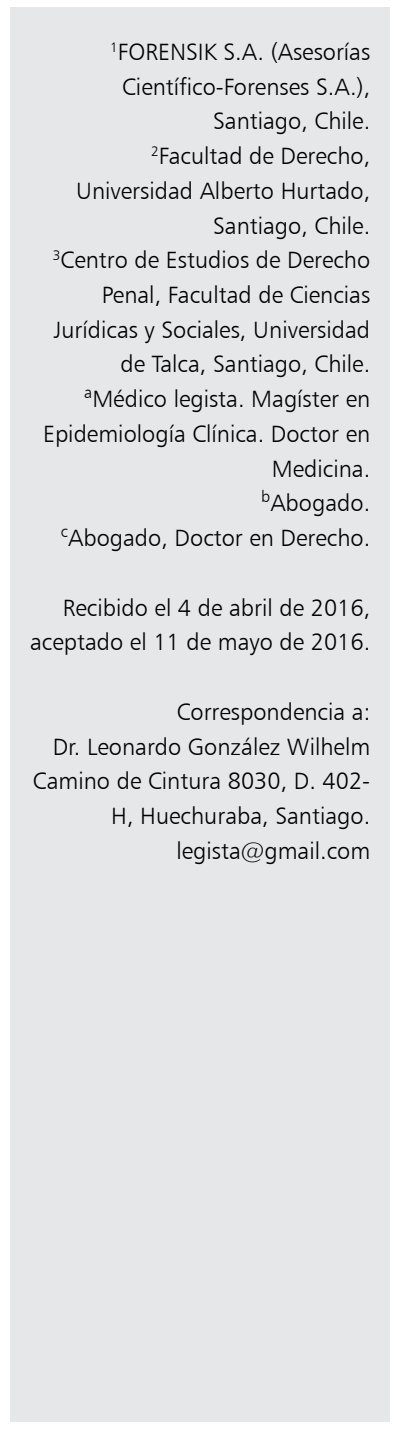

\section{Consideraciones médico-legales sobre causal de violación contenida en el proyecto de Ley de Aborto actualmente en trámite}

\author{
LEONARDO GONZÁLEZ-WILHELM ${ }^{1,2, a}$, \\ LEONARDO MORENO ${ }^{2, \mathrm{~b}}$, RAÚL CARNEVALI ${ }^{3, \mathrm{c}}$
}

\section{Medicolegal considerations about rape as a reason to decriminalize abortion}

The Chilean senate is discussing a proposal to decriminalize abortion in 3 causals. One of these is when the pregnancy occurs as a result of a rape. To be legally able to perform the abortion in this circumstance, a health care team must confirm the occurrence of the facts constituting the offence. Regardless of the patient's will, the accusation will be reported to the justice. In our view, in its current status the proposed rule does not consider certain medicolegal and procedural topics. Those flaws may determine in certain scenarios critical problems, such as: a) a wrongful conviction as a consequence of a false allegation of rape; (b) some pregnant due to a rape will not have access to the abortion procedure; (c) some accusations of rape will not be accredited nor criminally sanctioned. Employing a fictional case, we illustrate how those scenarios can actually be seen in practice. We also emphasize the difficulties and limitations that the health care team will encounter if the project is approved under the current conditions. Finally, we encourage the professional societies implicated in the theme to contribute in the legislatorial debate. Therefore, we give a set of proposals aimed to improve the bill before it may be enacted as a law.

(Rev Med Chile 2016; 144: 780-786)

Key words: Abortion, Legal; Abortion, Induced; Chile; Criminal Law; Legislation; Rape.
F inalizando el verano de 2017, Claudia, una joven de 18 años recién egresada del colegio, conoce en una fiesta a Jorge. Ambos congenian y comienzan un breve romance que finaliza la mañana siguiente, luego que mantuvieran relaciones sexuales consentidas. Posteriormente Claudia retorna a su ciudad y los jóvenes no tienen más contacto.

Semanas después ella constata que tiene un atraso menstrual. Se realiza entonces un test de embarazo, el cual resulta positivo. Claudia, quien no desea esa gestación, concurre a un centro asistencial, convencida que tras las modificaciones legales aprobadas poco tiempo antes tenía pleno derecho a solicitar un aborto.

Cuando la atienden, el médico le realiza una ecografía y verifica que se trata de un embarazo normal de 11 semanas, sin riesgo vital para la madre y con embrión aparentemente viable. Le aclara entonces a Claudia que sólo podría practicarse un aborto en caso que el embarazo hubiese sido producto de una violación. En esos momentos la joven, quien no ve alternativa, le manifiesta al facultativo que no recordaba bien lo sucedido porque ese día bebió mucho alcohol, pero estaba segura que no había querido tener relaciones 
sexuales con Jorge. Con todo, ante la duda ella había preferido no hacer una denuncia, lo cual quería mantener así.

Convocada la junta ad-hoc del equipo de salud, se analizó el caso. A esa fecha carecía de sentido obtener muestras para una alcoholemia o examen toxicológico para corroborar el relato de Claudia. Además, ya no existían rastros físicos de una acción violenta (ej. equimosis, erosiones, excoriaciones) y el examen sexológico sólo daba cuenta de un desgarro antiguo del himen (mayor a 7 días), compatible con una relación sexual pero insuficiente per se para asumir falta de consentimiento. Ante ese escenario los médicos (que no son jueces para decidir si existió o no un delito de violación) acogen lo expuesto por la paciente y se lleva a cabo la interrupción del embarazo. El facultativo a cargo completa además los formularios respectivos para que la dirección del establecimiento efectúe la correspondiente denuncia ante el Ministerio Público. También, diligentemente, resguarda con cadena de custodia parte del material obtenido tras el procedimiento, ante la eventualidad que pueda servir como evidencia.

Tras la denuncia se decretan diligencias, a partir de las cuales la policía ubica y entrevista tanto a Claudia como a Jorge. Ella reitera que no recordaba bien lo sucedido, pero creía que la habían violado. El joven en tanto, sorprendido, señala que sí conocía a Claudia y que había tenido relaciones sexuales consentidas con ella en una ocasión. Asimismo, ante la solicitud de una muestra de hisopado bucal, otorga su consentimiento manifestando que no ha hecho nada malo y por ende colaborará en lo que se le solicite.

La muestra en cuestión es comparada genéticamente con el material resguardado, estableciéndose que Jorge era el padre del embrión abortado. Con esa información el fiscal formaliza una investigación por violación y obtiene medidas cautelares contra Jorge.

Durante la investigación se ubica a otros jóvenes que participaron de la fiesta. Todos coinciden en afirmar que Claudia estuvo con Jorge. Algunos señalan además que éste le dio de beber mucho alcohol a la muchacha. La joven por su parte, rehúsa concurrir a declarar ante el fiscal. Sin embargo, asiste al Servicio Médico Legal (SML) y repite su historia: no recordaba bien lo sucedido, pero creía que la habían violado. El perito concluye que la mujer presentaba un desgarro himeneal antiguo y signos de un embarazo reciente, hallazgos que no permitían descartar una violación.

Tras concluir las indagatorias se realiza el Juicio Oral. Claudia -por miedo- no asiste a declarar, decisión que el persecutor penal respeta en función de lo consagrado en la Ley de aborto. Jorge se acoge al derecho de guardar silencio. $\mathrm{Su}$ defensa afirma que la supuesta víctima consintió plenamente el acto sexual. Manifiesta además que el caso se sustenta en una prueba obtenida con infracción de garantías, ya que el médico no estaba autorizado por la ley a resguardar tejidos del aborto. El fiscal afirma que Jorge, aprovechándose dolosamente de la ebriedad de Claudia, tuvo relaciones sexuales sin su consentimiento. Añade que el análisis genético se ajustó a derecho, porque el médico estaba obligado a practicar las pruebas biológicas conducentes a acreditar el hecho punible, debiendo conservar las muestras correspondientes.

El tribunal efectúa el debate de rigor y termina condenando a Jorge. Dado que el joven tenía antecedentes penales por un accidente de tránsito, se decreta el cumplimiento efectivo de la pena. La defensa recurre de nulidad, pero la I. Corte de Apelaciones confirma la sentencia. Jorge es encarcelado como autor del delito de violación.

Cuando Claudia se entera, pide ayuda a un abogado. Se redacta un recurso de revisión, en el cual ella se retracta de sus dichos. Sin embargo, el libelo no es admitido a trámite por la Corte Suprema, dado que nuestra legislación establece que "no podrá probarse por testigos los hechos en que se funda la solicitud de revisión”.

\section{Discusión}

En Chile, aproximadamente 2,1\% de los abortos estarían motivados porque el embarazo fue producto de violación ${ }^{1}$. Aun cuando importantes autores nacionales han opinado que la práctica de un aborto mandatada por ley no constituiría un acto médico, sino más bien, un gesto con significación social ${ }^{2}$, desde la óptica médico-legal discrepamos, porque consideramos que el procedimiento también puede ser trascendente a título individual (en el status bio-psico-social de la mujer que lo solicita). Además, la correcta interpretación de hallazgos al examen sexológico requiere de competencias y conocimientos propios de nuestra especialidad. Dado ello e independiente de consi- 
deraciones de fondo sobre la legitimidad de una ley de aborto, creemos que las meras implicancias prácticas para el ejercicio profesional debieran motivar a la comunidad médica a involucrarse en el debate del proyecto que actualmente cumple su segundo trámite legislativo. Por tal motivo, hemos considerado necesario alertar -mediante el caso ficticio expuesto- sobre ciertas cuestiones relevantes que no han sido discutidas en torno a la causal de violación.

El elemento central de análisis es que la actual propuesta ${ }^{3}$ carece de resguardos suficientes e idóneos, permitiendo así que la decisión de abortar pueda eventualmente desencadenar un error judicial. En el ejemplo, Claudia jamás quiso perjudicar a Jorge. Sin embargo, ante la obligatoriedad de expresar una causa para la deseada interrupción del embarazo, la joven dio inicio a un proceso cuya trascendencia e irreversibilidad difícilmente pudo prever. No ha de olvidarse además que la mujer que recurre al aborto está bajo presión, con gran angustia $y$, probablemente, sentimientos de culpabilidad ${ }^{4}$.

Pero la consecuencia indeseada citada no es la única posible. El hecho que la normativa en discusión no tenga en cuenta ciertas cuestiones médico-legales y procesales puede también:

a) Permitir situaciones en las cuales una oportuna solicitud de aborto por parte de una embarazada producto de violación no sea acogida.

b) Comprometer la posibilidad que los casos de violación puedan ser efectivamente acreditados y sancionados penalmente.

A continuación analizaremos detalladamente cada uno de los escenarios expuestos:

\section{La posibilidad de una condena errada por falsa denuncia de violación}

Independiente si la motivación es dolosa (con la intención de causar daño) o -como en el caso ejemplificado- culposa ( $\sin$ atender a las consecuencias), lo concreto es que el proyecto actualmente en trámite no otorga garantías que aseguren la oportuna pesquisa de una falsa denuncia de violación. A juicio nuestro y de otros autores, el principal problema radica en el hecho que la norma propuesta sólo provee un asomo de autonomía para la mujer ${ }^{5,6}$, escenario en el cual la embarazada puede verse persuadida a aducir engañosamente la causal de violación. A ello se suma la impropia facultad otorgada al equipo de salud, que deberá "confirmar la concurrencia de los hechos que constituyen" la violación. Pero... ¿cómo, si ello es médicamente imposible?

Aunque parezca obvio, se ha de recordar que la violación es un delito, no una enfermedad. Por ende, concordando con lo públicamente expuesto por el Subdirector Médico del SML, ningún médico y en ninguna circunstancia, puede certificar una violación ${ }^{7}$. Ahora bien, es posible que el ejecutivo y los parlamentarios -al igual que sucede a diario con muchos operadores de la justicia- hayan creído erradamente que en una violación necesariamente existirá algún rastro de violencia física compatible con el hecho. Sin embargo, la evidencia científica demuestra todo lo contrario. En efecto, existe amplio consenso que en la mayor parte de los casos en que se sospecha una agresión sexual no habrá signos de lesiones significativas, trauma cicatrizado o enfermedades de transmisión sexual ${ }^{8}$. Ello es válido tanto para niños ${ }^{9-13}$, adolescentes ${ }^{10,14}$ y adultos ${ }^{15,16}$.

Aun cuando se produzcan lesiones por la violación, éstas suelen ser superficiales y lo común es que sanen en pocos días, muchas veces sin dejar marcas ${ }^{17-20}$. Cabe considerar además que una relación sexual consentida también puede dar lugar a lesiones, las cuales no poseen en términos generales un patrón morfológico distintivo respecto de las producidas en un acto no consentido ${ }^{16,21-23}$.

Por otra parte, las víctimas de un delito sexual no siempre manifiestan cambios conductuales o trastornos psicosomáticos en respuesta a los hechos. Aun cuando ello suceda, se trata de indicadores inespecíficos que han de ser interpretados con cautela ${ }^{24-27}$.

Visto lo anterior, resulta comprensible un paradigma de la sexología forense actual: la existencia de lesiones no ha de ser entendida como sinónimo de violación y la ausencia de ellas tampoco permite descartar el delito. Así entonces, cualquier apreciación sobre si hubo o no delito queda en definitiva condicionada al relato de la supuesta víctima. De hecho, acorde a nuestro marco legal (Tabla 1) y tratándose de mujeres mayores de 14 años, lo esencial no es la valoración médica sino la ponderación de si el acto sexual fue o no consentido. Y ello es una labor que debiera competir exclusiva y excluyentemente a la justicia, no al equipo de salud. 
Tabla 1. Evolución histórica contemporánea del marco legal que sanciona el delito de violación en Chile

\begin{tabular}{|c|c|c|}
\hline Ley & Año & Puntos destacados \\
\hline 19.617 & 1999 & Define como violación el acceso carnal por vía vaginal, anal o bucal, sin el consentimiento de la víctima \\
\hline 19.874 & 2003 & Concede siempre acción penal pública a delitos sexuales cometidos en menores de edad \\
\hline 19.927 & 2004 & $\begin{array}{l}\text { Aumenta de } 12 \text { a } 14 \text { años la edad mínima para considerar legalmente válido el consentimiento al acto } \\
\text { sexual }\end{array}$ \\
\hline 20.084 & 2005 & $\begin{array}{l}\text { Establece en su Art. } 4 \text { reglas especiales para la persecución penal de violaciones cometidas por ado- } \\
\text { lescentes }\end{array}$ \\
\hline 20.207 & 2007 & Modifica el plazo de prescripción del delito de violación en caso que la víctima sea menor de edad \\
\hline 20.480 & 2010 & Modifica concepto de incapacidad para oponerse al acto sexual \\
\hline
\end{tabular}

Para efectos prácticos, a partir del proyecto la sentencia judicial del delito de violación se sustituye por la mera afirmación de una relación sexual no consentida ${ }^{28}$. En ese escenario, lo esperable y éticamente correcto en función de los intereses de la paciente y el principio de no-maleficencia, es que el médico (en rigor, el comité ad-hoc que se designe para tales fines) sencillamente le crea y proceda a realizar el aborto y posterior denuncia. Sin embargo, a partir de allí se desencadena una avalancha de sucesos de impredecible evolución. Si bien existe en teoría la posibilidad que el proceso penal no se inicie (por archivo provisional de la causa) o concluya sin un juicio (por decisión de sobreseer o no perseverar), es también plausible que en determinadas circunstancias -lo que partió como una solicitud de aborto- concluya con un hombre inocente tras las rejas. Y ello, a la luz del actual proyecto de ley, sin que siquiera la supuesta víctima efectúe denuncia ni preste declaración judicial.

\section{La posibilidad que una embarazada producto de violación no acceda al aborto}

Ante la inexistencia de criterios médicos válidos, pudiera darse el caso que el comité designado al efecto dude de la versión de la paciente y no "confirme" la violación. En el ejemplo expuesto la junta ad-hoc también pudo concluir que -la ausencia de lesiones e inexistencia de exámenes toxicológicos, sumado a la incerteza de Claudia sobre las circunstancias del hecho- resultaban criterios suficientes para dudar que el embarazo fuese producto de una violación. Consecuentemente pudieron haberle negado el aborto.
Sin embargo, en una época en que la incidencia de delitos sexuales facilitados por drogas ha aumentado $^{29}$, en teoría el relato de Claudia perfectamente pudo no tener motivaciones gananciales, sino ser la genuina expresión de un delito cometido mediante el uso - proactivo u oportunista- de algún agente químico ${ }^{30-34}$. En tal sentido, cabe tener presente que las manifestaciones sedantes, hipnóticas o propiedades amnésicas de las drogas utilizadas en esos casos alteran la conducta de la víctima, aumentando su susceptibilidad a sufrir un ataque de esta naturaleza y disminuyendo la posibilidad de recolectar ad post información sobre los eventos que rodearon el hecho. Dado ello, lo característico es que las personas agredidas sólo perciban la sensación de haber sido violadas, no teniendo recuerdos del ataque o siendo estos muy vagos y fragmentados ${ }^{30,31}$.

Visto lo anterior, creemos que la actual redacción del proyecto de ley de aborto no ha contemplado situaciones como la descrita, dejando vacíos que -en determinadas circunstancias- pueden condicionar que el espíritu de norma no llegue a materializarse.

\section{La posibilidad que violaciones no sean acreditadas y sancionadas penalmente}

En el caso ficticio expuesto, el fiscal inició de oficio una investigación y continuó su tramitación hasta llegar a juicio. Sin embargo, dado que Claudia era mayor de edad, el persecutor también tuvo la alternativa de no acceder a esa instancia. Por tanto, si la joven realmente hubiese sido violada por Jorge, éste pudo permanecer impune ante la ley. Y la causa de eso radica en una cues- 
tión procesal: el delito de violación cometido en mayores de edad no siempre es de acción penal pública.

Por otra parte, en el ejemplo, la evidencia para demostrar inequívocamente que Jorge tuvo una relación sexual con Claudia fue la comparación genética de lo resguardado tras el aborto con la muestra de hisopado bucal que aportó el joven.

Lejano a ese escenario ideal, el actual proyecto no contempla la conservación de muestras para ser usadas como evidencia en un proceso penal. Por el contrario: la norma en discusión establece sanciones para quien "facilitare o proporcionare a otro cualquier órgano, tejido o fluido humano proveniente de aborto o interrupción del emba-

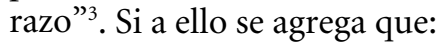

- salvo orden judicial, la obtención de muestras orgánicas de un imputado está condicionada a su voluntad;

- habitualmente no hay testigos de un delito sexual;

- la denuncia del hecho frecuentemente es tardía;

- los hallazgos al examen sexológico nunca son concluyentes ni mucho menos vinculantes para la decisión judicial;

el escenario para el persecutor penal se torna inmensamente complejo, por cuanto puede quedar reducido a la mera confrontación de la versión de la supuesta víctima (quien según lo consagra el proyecto, puede decidir no comparecer a los actos del procedimiento) con los dichos del acusado (quien a su vez, puede acogerse al derecho de guardar silencio).

Ahora bien, pudiera ocurrir que sí se resguarden muestras en atención a lo dispuesto en el Art. 198 del código procesal penal. Sin embargo, a nuestro entender nada impide que un juez de garantía o tribunal oral en lo penal considere que ello constituye una actuación procesal ilegítima, excluyendo de la valoración cualquier prueba generada a partir de esa evidencia. Peor aún, dependiendo de la interpretación que se haga, el médico que realizó el procedimiento pudiera incluso ser penado e inhabilitado para el ejercicio de la profesión ${ }^{3}$.

Siendo la violación un delito de difícil prueba, creemos entonces que el actual proyecto de ley dificulta aun más las cosas. En tal sentido, la inadvertida restricción para la obtención y conservación de evidencias resulta equivalente a una norma que prohíba la toma de muestras de contenido vaginal, anal y/o bucal en cualquier otro denunciante de violación.

\section{Conclusiones}

La voluntad de legislar en materia de violación y aborto ha sido aprobada por nuestros parlamentarios y este trabajo de modo alguno pretende desalentarla. Habida cuenta de ello, consideramos que la actual redacción del proyecto de ley puede originar problemas complejos que no han sido advertidos durante su tramitación. Estos dicen relación con circunstancias en las cuales el espíritu de la norma puede llegar a no materializarse en la práctica o generar efectos adversos socialmente reprochables, tales como la condena errada de un inocente o la eventual no sanción penal de un culpable de violación. Para evitar esos escenarios, resulta recomendable que la legislación actualmente en trámite sea modificada en lo que respecta a la causal de violación. Creemos por tanto que los colegios profesionales implicados en el tema (ej. médicos, matronas, enfermeras, abogados) debieran participar activamente de la actual discusión en el Senado, proponiendo:

1. Que el equipo que se conforme para "confirmar la concurrencia de los hechos que constituyen" la violación esté integrado también por abogados del staff jurídico de la institución asistencial o del Servicio de Salud correspondiente.

2. Que la conclusión a la que arribe esa junta ad-hoc sea debidamente fundada y registrada en un formulario de formato único distribuido por el Ministerio de Salud. El diseño de dicho documento ha de ser establecido en el reglamento de la ley y ser producto del trabajo conjunto del Poder Judicial, Ministerio de Salud, Ministerio de Justicia, universidades y colegios profesionales.

3. Que tratándose de mayores de 14 años, la interrupción del embarazo antes de las 12 semanas de edad gestacional se restrinja exclusivamente a aquellas mujeres que acrediten haber recibido una atención médica por Ley 19.617 en las 2 semanas siguientes a la supuesta violación. Ese plazo se basa en el tiempo que habitualmente 
tarda un test rápido de embarazo en tornarse positivo $^{35}$. La medida:

- permitiría circunscribir la prestación del aborto a aquellas mujeres que manifestaron la causal de violación sin conocer su condición de embarazada.

- promovería una consulta precoz, lo que pudiera evitar un aborto mediante la indicación de anticoncepción de emergencia -o subsidiariamente- optimizaría el rendimiento del programa de acompañamiento, la atención integral de la paciente y la recolección de evidencias para la acreditación penal del ilícito.

4. Que se establezca explícitamente que, en abortos por esta causal, el delito de violación será siempre de acción penal pública. Ello contribuiría a evitar que casos queden impunes por falta de persecución penal.

5. Que se excluya del Art. 345 bis del proyecto, aquellas actuaciones tendientes a resguardar evidencia acorde a las disposiciones del Art. 198 del código procesal penal.

6. Que se destinen recursos específicos para una eficaz educación cívica y permanente publicidad del eslogan "Si fuiste víctima de violación, consulta a tu médico antes de dos semanas".

\section{Referencias}

1. Koch E. Editorial. Epidemiología del aborto y su prevención en Chile. Rev Chil Obstet Ginecol 2014; 79 (5): 351-60.

2. Echeverría C, Serani A, Arriagada AM, Goic A, Herrera C, Quintana C, et al. Consideraciones acerca de la "interrupción voluntaria del embarazo", desde el punto de vista ético-médico (a propósito de un proyecto de ley). Rev Med Chile 2015; 143: 1478-83.

3. Oficio $\mathrm{N}^{\circ} 12.408$ de la Cámara de Diputados de Chile, de fecha 17-03-2016. Disponible en: http://bit.ly/1RntVuc [Consultado el 24 de marzo de 2016].

4. Gayán P. El derecho a la vida. Legislación en relación al aborto. Rev. Obstet Ginecol Hosp. Santiago Oriente Dr. Luis Tisné Brousse 2007; 2 (1): 9-11.

5. Kottow MH. Aborto: tomando el debate en serio. Medwave 2015; 15 (4): e6139.

6. Aylwin T. Aborto en caso de violación, machismo puro. Disponible en: http://bit.ly/1RnOj0k [Consultado el 24 de marzo de 2016].

7. De Améstica C. Subdirector del Servicio Médico Legal:
"Nunca el médico puede certificar una violación". Disponible en: http://bit.ly/1T46ivl [Consultado el 24 de marzo de 2016].

8. Adams JA. Medical evaluation of suspected child sexual abuse: 2011 update. J Child Sex Abus 2011; 20 (5): 588605.

9. Guidelines for the evaluation of sexual abuse of children: subject review. American Academy of Pediatrics Committee on Child Abuse and Neglect. Pediatrics 1999; 103 (1): 186-91.

10. Kellogg ND, Menard SW, Santos A. Genital anatomy in pregnant adolescents: "normal" does not mean "nothing happened". Pediatrics 2004; 113 (1 Pt 1): e67-9.

11. Adams JA. Medical evaluation of suspected child sexual abuse. J Pediatr Adolesc Gynecol 2004; 17 (3): 191-7.

12. Berkoff MC, Zolotor AJ, Makoroff KL, Thackeray JD, Shapiro RA, Runyan DK. Has this prepubertal girl been sexually abused? JAMA 2008; 300 (23): 2779-92.

13. Jenny C, Crawford-Jakubiak JE. The evaluation of children in the primary care setting when sexual abuse is suspected. Pediatrics 2013; 132 (2): e558-67.

14. White C, McLean I. Adolescent complainants of sexual assault; injury patterns in virgin and non-virgin groups. J Clin Forensic Med 2006; 13 (4): 172-80.

15. Rauch E, Weissenrieder N, Peschers U. Sexualdelikte-Diagnostik und Befund interpretation. Dtsch Arztebl Int 2004; 101 (B): 2257-63.

16. McLean I, Roberts SA, White C, Paul S. Female genital injuries resulting from consensual and non-consensual vaginal intercourse. Forensic Sci Int 2011; 204 (1-3): 27-33.

17. Heppenstall-Heger A, McConnell G, Ticson L, Guerra L, Lister J, Zaragoza T, et al. Healing patterns in anogenital injuries: a longitudinal study of injuries associated with sexual abuse, accidental injuries, or genital surgery in the preadolescent child. Pediatrics 2003; 112 (4): 82937.

18. Smith WG, Metcalfe M, Cormode EJ, Holder N. Approach to evaluation of sexual assault in children. Experience of a secondary-level regional pediatric sexual assault clinic. Can Fam Physician 2005; 51: 1347-51.

19. Reznic MF, Nachman R, Hiss J. Penile lesions-reinforcing the case against suspects of sexual assault. J Clin Forensic Med 2004; 11 (2): 78-81.

20. Lahoti SL, McClain N, Girardet R, McNeese M, Cheung K. Evaluating the child for sexual abuse. Am Fam Physician 2001; 63 (5): 883-92.

21. Anderson SL, McClain N, Riviello RJ. Genital findings of women after consensual and nonconsensual intercourse. J Forensic Nurs 2006; 2 (2): 59-65.

22. Anderson SL, Parker BJ, Bourguignon CM. Changes in 
genital injury patterns over time in women after consensual intercourse. J Forensic Leg Med 2008; 15 (5): 306-11.

23. Frioux SM, Blinman T, Christian CW. Vaginal lacerations from consensual intercourse in adolescents. Child Abuse Negl 2011; 35 (1): 69-73.

24. Shackel RL. The beliefs commonly held by adults about children's behavioral responses to sexual victimization. Child Abuse Negl 2008; 32 (4): 485-95.

25. Paras ML, Murad MH, Chen LP, Goranson EN, Sattler $\mathrm{AL}$, Colbenson KM, et al. Sexual abuse and lifetime diagnosis of somatic disorders: a systematic review and meta-analysis. JAMA 2009; 302 (5): 550-61.

26. Lindblad F, Lainpelto K. Sexual Abuse Allegations by Children with Neuropsychiatric Disorders. J Child Sex Abus 2011; 20 (2): 182-95.

27. Johnson CF. Child sexual abuse. Lancet 2004; 364 (9432): 462-70.

28. Las claves del proyecto de ley que despenaliza el aborto. Disponible en: http://bit.ly/21Dy6XD [Consultado el 24 de marzo de 2016].
29. Epidemiology of Drug-Facilitated Crimes and Drug-Facilitated Sexual Assaults. En Kintz, P. Toxicological aspects of Drug-Facilitated crimes. Academic Press, Elsevier Inc.; 2014. p. 11-46.

30. Le Beau MA, Mozayani A. Drug-facilitated sexual assault. A forensic handbook. Londres, Reino Unido: Academic Press; 2001.

31. Bechtel LK, Holstege CP. Criminal poisoning: drug-facilitated sexual assault. Emerg Med Clin North Am 2007; 25 (2): 499-525.

32. Bosman IJ, Verschraagen M, Lusthof KJ. Toxicological findings in cases of sexual assault in the Netherlands. J Forensic Sci 2011; 56 (6): 1562-8.

33. Du Mont J, Macdonald S, Rotbard N, Bainbridge D, Asllani E, Smith N, et al. Drug-facilitated sexual assault in Ontario, Canada: toxicological and DNA findings. J Forensic Leg Med 2010; 17 (6): 333-8.

34. Hall JA, Moore CB. Drug facilitated sexual assault-A review. J Forensic Leg Med 2008; 15 (5): 291-7.

35. Chard T. Pregnancy tests: a review. Hum Reprod 1992; 7 (5): 701-10. 